\title{
Sickle Cell Disease in Sub-Saharan Africa: Molecular Mechanisms Underlying Episodic Crises, Current and Emerging Therapeutic Strategies in Treatment

Ajonuma Louis Chukwuemeka1,3, Yusuf Azeez¹, Bamiro Adebisi Saka1, Makonjuola Samira Lobo², Ajuonuma Udochukwu Joshua ${ }^{3}$, Ajuonuma Mary Uchechi ${ }^{3}$, Emmanuel Blessing Chioma ${ }^{3,4}$, Ogbedeagu Virgilus Mahakwe ${ }^{5}$, Chuku Chika Lawson ${ }^{6}$, Adabale Khedijat Abosede ${ }^{7}$

Dosunmu Adedoyin Owolabi

\section{Abstract}

Sickle cell disease (SCD) is a haematological disease that affects multiple organs, thus eliciting episodes of chronic pain, acute anaemia and infection, due to a single nucleotide mutation in the $\beta$-globin gene, which results in the substitution of a glutamic acid residue in place of valine on the $\beta$-globin chain of the resultant haemoglobin protein molecule, the sickle haemoglobin ( $\mathrm{HbS}$ ). SCD is a major cause of morbidity and mortality characterized by episodes of vaso-occlusive crises, pain syndromes and end organ dysfunctions. Its global prevalence is highest in Sub-Saharan Africa with $75 \%$ of global births living in this region, of which Nigeria has the highest number of SCD patients with about 100.000 births each year. The burden of SCD in the sub-Saharan region of Africa is enormous. Emotional, financial and total healthcare costs are monumental. An understanding of the mechanism underlying the vaso-occlusive crises, pain syndromes, inflammatory conditions and other sequelae of SCD appears to be essential in providing more rational treatments. The present review discuses the prevalence of SCD in Africa, molecular mechanisms underlying SCD episodic crises including vaso-occlusive syndrome, anaemia and infection. Current available treatments modalities in Sub-Saharan Africa and possible new treatment methods that cure SCD are re-examined in light of these mechanisms.
1 Department of Physiology, Lagos State University College of Medicine, Ikeja, Lagos, Nigeria.

2 Department of Pharmacology, Lagos State University College of Medicine, Ikeja, Lagos, Nigeria.

3 St. Marys' Hospital Amakohia, Ihitte - Uboma, Imo State, Nigeria.

4 School of Nursing, Imo State University, Owerri, Imo State, Nigeria.

5 University of Abuja Teaching Hospital, Gwagwalada, Abuja, Nigeria.

6 Department of Internal Medicine, Braitheweith Specialist Hospital, Port Harcourt, Rivers State, Nigeria.

7 Department of Hermatology, Lagos State University College of Medicine, Ikeja, Lagos, Nigeria.

Contact information:

Ajonuma Louis Chukwuemeka. Department of Physiology, Medical Research Complex.

Address: Lagos State University College of Medicine (LASUCOM), 1-5 Oba Akinjobi Way, Ikeja, Lagos, Nigeria.

Tel: +2347012436468

”Louisca@alumni.cuhk.net 


\section{Introduction}

Sickle cell disease (SCD) is a haematological disease that affects multiple organs through episodes of acute illnesses such as chronic pain, acute anaemia and infection, in both children and adults. The disease develops due to a single nucleotide mutation in the $\beta$-globin gene, which results in the substitution of a glutamic acid residue at the $\sigma^{\text {th }}$ position into a valine on the $\beta$-globin chain of the resultant haemoglobin protein molecule, the sickle haemoglobin (HbS). This causes the formation of a defective protein that affects the structure of the red blood cell (RBC), producing a sickle shaped cell [1]. As an autosomal recessive disorder, SCD is the one of the most common monogenic disorders known and it is characterized by phenotypic heterogeneity due to occurrence of various types of mutation in the $\beta$-globin gene [2]. The predominant clinical phenotype is the homozygote HbSS otherwise called the sickle cell anaemia (SCA), while other complex heterozygotes also exist due to different mutation in the $\beta$-globin gene. For instance the $\mathrm{HbS}-\beta$ thalassemia, HbSC (with HbSS in Africa), HbSO and $\mathrm{HbCO}$ (Arab) and HbD (Punjab) all exist to constitute what is known as SCD [3-5]. The African HbS globin haplotypes are present in three geographical locations, Senegal, Benin and Bantu regions with a fourth Arab-Indian haplotype believed to have originated from Arab slave trades in Africa [6]. The HbS gene exists in high frequency in populations that experienced a selective pressure from Plasmodium falciparum, a protozoan agent for malaria because the resulting HbAS heterozygote is conferred with some form of protection against the deleterious consequences of malaria. As such, SCD exists in high prevalence in areas where malaria is endemic.

SCD is a major cause of morbidity and mortality, and its global prevalence is highest in Africa, South America, India, Middle East and the Caribbean [7]. The highest global prevalence of SCD is in Sub-Saharan Africa with $75 \%$ of global births existing in this region and within this region, Nigeria has the highest number of SCD patients with about 100,000 births each year amounting to 33\% of global annual births $[8,9]$. It has been reported that childhood mortality due to the disease in Africa ranges between 50-90\%, although accurate information on this information is still lacking [10]. According to the World Health Organisation, $70 \%$ of deaths of SCD patients in Africa is preventable through low cost interventions such as new born screening for early identification of SCD patients and comprehensive care provision for disease prevention [11]. Although, increased incidence of mortality in children has been nearly eliminated in North American continent due to advancement in medical care and new born screening as well as provision of prophylactic antibiotics and pneumococcal vaccinations to prevent infection $[12,13]$, these still constitute a disease management that is not curative. The major forms of treatment available in this part of the world with significant effect include heamatopoietic stem cell transplant (HSCT), bone marrow transplant and red cell transfusion. Currently, only HSCT successfully carried out using stem cells or haematopoietic stem cells that have been genetically modified (gene therapy) can result in total cure by restoring normal erythropoiesis [14].

With the exception of South Africa where there are stem cell transplant centres [15], unfortunately in most parts of Africa, there is currently no curative treatment and the major form of treatments that have been in use in the region includes blood transfusion and prophylactic treatments. For instance, a new study reported that health care centres in Nigeria now prescribe patients with hydroxyurea (for those who can afford the drug when prescribed), folate supplements and penicillin prophylaxis [16]. Based on these facts, the treatment modalities currently available in sub Saharan Africa does not suffice for the burden of morbidity due to the disease in the continent harbouring more than 50\% of the affected individuals with SCD. Here, we review the current treatment modalities in Africa and 
suggest ways of better managing the disease as well as providing timely and effective treatments for patients with SCD.

\section{Results}

\section{Signs and Symptoms of SCD}

SCD is a haematological disease that stems from the production of defective RBCs. Nonetheless, patients suffering from the disease presents with a number of clinical signs and symptoms that represent multisystem failure/organ damage. The major symptoms are mainly categorized into three; haematological complications and associated syndromes, vaso-occlusive crises and pain syndromes, and end organ dysfunction.

\section{Haematological complications and associated syndromes}

SCD is a disease of the blood and it is mainly associated with complications arising from dysfunction of the RBCs. Chronic anaemia is a classic symptom in SCD patients occurring throughout their lives. Depending on genotype, the severity of anaemic crises in SCD varies and patients with homozygote HbSS experiencing the most severe anaemia due to the highest reduction in haemoglobin level, while those with $\beta$-thalasemia experience the least severe crises. Although SCD patients do not present with anaemia at birth due to protection from foetal haemoglobin $(\mathrm{HbF})$, anaemia arises due to production of the adult $\mathrm{Hb}$ later in life resulting in acute episodes of haemoglobin reduction, hence anaemic crises. During the first five years of life, the $\mathrm{Hb}$ level remains virtually stable, although clinically significant lowering of $\mathrm{Hb}$ do occur at intervals resulting in such secondary symptoms as hyperhaemolysis, splenic complications, and aplasia.

Although severe anaemia is a hallmark of SCD, hyperheamolysis is characterised with accelerated drop in steady state level of $\mathrm{Hb}$ with a corresponding increased rate of haemolysis. It is also occasionally accompanied with increased erythropoiesis, increase in steady state reticulocyte count (about 25\%) and exaggerated hyperbilirubnemia which may result in gall bladder disease $[8,17]$. Hyperhaemolysis sometimes results during RBC transfusion where delayed haemolytic transfusion reaction causes destruction of both autologous and homologous RBCs by an innocent bystander mechanism. This coupled with transfusion induced suppression of erythropoiesis leads to the marked increase in haemolysis and is often followed with reticulocytopenia [18].

Splenic complications are one of the most observed crises in patients with SCD particularly those with SCA during the early stage of the disease and they are associated with increased morbidity and mortality. Acute splenic sequestration occurs in the first decade after birth and can occur as early as 2 months after birth due to excessive sequestration of both normal and sickled RBC into the spleen often resulting in severe anaemia and splenomegaly [19]. This thus leads to reduction in the level of $\mathrm{RBC} / \mathrm{Hb}$ present in the blood by $>2 \mathrm{~g} / \mathrm{dL}$, increased reticulocytosis and thrombocytopenia most times affecting packed cell volume [20]. These are the classical signs observed during aplastic crisis, although it is usually induced by infection such as that of parvovirus B19. Infection of erythroid progenitor cells in peripheral blood and bone marrow by parvovirus B19 results in cessation of erythropoiesis for as much as 10 days resulting in severe anaemia due to very short life span of RBC in SCD.

Priapism, a painful and prolonged penile erection occurs in about $30 \%$ of adolescents with SCD and it is as a result of increased arterial inflow of blood with reduced venus outflow causing the trapping of RBCs in erectile bodies. It has been determined to be associated with increased haemolysis, since haemolysis results in depletion of nitric oxide (NO), an important smooth muscle cell relaxant that plays important role regulating erectile functions [21]. 
Haemolysis remains a major life threatening event in SCD patients mainly because of the secondary complications that arises as a result. One of the most common symptoms of SCD is the acute chest syndrome (ACS) [22]. Adults suffering from SCD are at high risk of developing systemic and pulmonary hypertension, impaired vasodilatation due to changes in the intima and smooth muscles of blood vessels, and endothelial dysfunction [23]. With disease progression and age, there is increase in the burden of morbidity due to end organ failure such as avascular bone necrosis as a result of bone marrow infarction, chronic nephropathy due to haematuria, hyperfiltration, microalbuminuria and proteinuria, and haemorrhagic and non-haemorrhagic stroke [24-26].

\section{Vaso-occlusive crises and pain syndromes}

Vaso-occlusion is the major symptom and complications observed in SCD patients resulting ultimately in painful episodes $[27,28]$. Vaso-occlusion arises due to the obstruction of micro-vessels consequent of trapped sickled RBCs resulting in ischemia induced organ damage and painful episodes lasting from few hours to days or even weeks beginning from early childhood to adolescence, aggravating in adulthood when there may be persistent acute pain in the bones and joints. It results in body pains affecting different parts of the body and it is believed also to be the cause of priapism and splenomegaly due to acute splenic sequestration [29] as stated above. Recurrent acute pain episodes may result in neurological changes that may heighten sensitivity to pain. ACS is also a common occurrence in SCD characterised with chest pain, wheezing, cough, refractory hypoxemia and tachypnea, and it is as a results of the obstruction of micro-vessels by sickled RBCs [30].

\section{Leg Ulcer}

Leg ulcers are relatively common complications of SCD and can be debilitating. It is uncommon in the first decade of life. Pathogenesis of chronic leg ulcers in SCD is complex and may be due to the following factors: 1) Mechanical obstruction of the microcirculation by dense sickled RBCs, 2) bacterial infections, 3) chronic anaemia due to hemolysis with decrease in RBCs oxygen carrying capacity, 4) decreased nitric oxide bioavailability leading to impaired endothelial function. Production of endothelin-1, a potent vasoconstrictor and subsequent increased expression of endothelial cells adhesion molecules, thrombosis and venous incompetence have all been proposed as potential contributing factors [31, 32].

Most of the time it is on the dependent part, especially the lower extremities that are involved, in areas with thin skin, less subcutaneous fat and with decreased blood flow (Figure 1). Trauma and inflammatory conditions may be the initiating factors.

Figure 1: A photomicrograph showing a leg ulcer that resulted from a trauma more than one year ago in a 25 years old female SCD patient. The ulcer is necrotic, with gangrenous borders, full thickness skin loss, destruction of other supporting structures and possible accompanying osteomylitis. SCD = Sickle cell disease

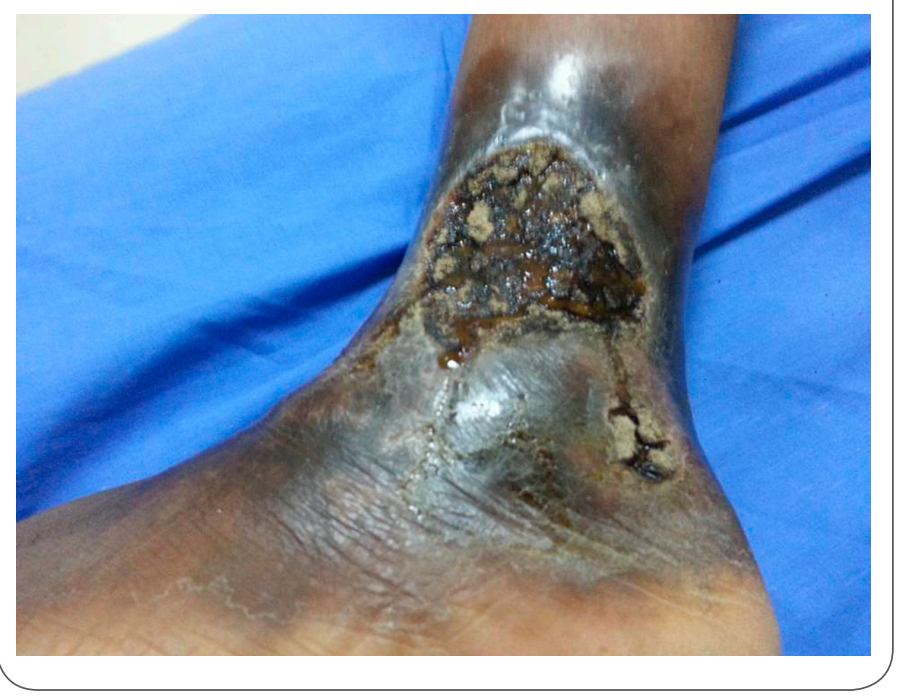

\section{End organ dysfunction}

Advancement in treatment of SCD has increased the survival rate in SCD patients but due to frequent episodes of haemolytic anaemia, ischemia and reperfu- 
sion injury in different organs, this group of people develop progressive organ dysfunction and eventual organ failure. SCD is associated with cardiovascular abnormalities due to increased cardiac output and resultant morphologic and physiologic changes to the cardiac system. Such changes include thickened ventricular septum, left ventricular hypertrophy and abnormal left ventricular diastolic function leading to overt cardiovascular dysfunction [33]. Pulmonary hypertension is a common end organ complication that is seen in about 30\% of SCD adults, posing a major life threat and increasing mortality. Patients with pulmonary hypertension have reduced NO in the circulation due to chronic anaemia and as a consequent, there is development of vasculopathies characterised with endothelial dysfunction, increase in vascular tone, hypercoagulability and remodelling/destruction of the pulmonary vasculature [34]. Such patients present with ACS accompanied by severe pain that is ameliorated with NO inhalation. Patients with ACS present with cough, fever, chest pain, hypoxia, dyspnoea and wheezing due to pulmonary infection that arises from colonisation of the upper respiratory tract with bacteria or viruses such as E. coli, Streptococcus pneumonia, Staphylococcus aureus and Haemophilus influenzae [22, 35]. Bone marrow infarction and subsequent pulmonary infarction or fat embolism due to thromboembolism in micro-vessels have also been observed from autopsy reports of SCD patients and has also been associated with SCD and as such can be diagnosed using bronchioalveolar lavage to examine lipid laden macrophages [36].

\section{Pathophysiology of SCD}

\section{Molecular mechanisms of RBC membrane fragility and haemolysis in SCD}

The normal $\mathrm{Hb}$ molecule is highly soluble and its solubility is the main property that allows RBCs to easily bind the molecule in high concentration to facilitate transport of oxygen molecule efficiently. The RBCs possess structural flexibility that aids loading and unloading of oxygen molecules, thus, when the $\mathrm{Hb}$ molecule is deoxygenated and passed into the microcirculation, it undergoes a structural change to allow oxygenation traversing the pulmonary circulatory system. The replacement of glutamic acid in the $\beta$-globin molecule of $\mathrm{HbS}$ with valine results in hydrophobic interaction between adjacent deoxy-HbS molecules on the $\beta$-globin chain forming polymeric units. This event characterises the initiation, chain extension and stabilisation of a polymeric fibre of deoxy-HbS moieties which also groups together forming a fragile structure that disrupts the cytoskeletal framework and stiffens the structure of RBCs resulting in a sickled shape cells with very limited structural flexibility or reduced deformability [6]. The polymeric deoxy-HbS fibre in turn triggers the activation of signalling cascades that initiates the pathophysiological mechanism.

Because of the rigidity of the cell, dysregulation of ion transport across the membrane is affected. Most importantly, there is activation of ion channels such as the calcium dependent potassium channel (Gardos channel) and the potassium chloride cotransport system activation of which causes an influx of $\mathrm{Ca}^{2+}$ and a concomitant outflux of $\mathrm{K}^{+}$resulting in RBC dehydration. This in turn increases the intracellular concentration of $\mathrm{Hb}$ and thus favours polymerisation of more deoxy-HbS [37]. Intracellular hemichromes from denatured $\mathrm{Hb}$ interacts with band 3 proteins, spectrin and actin leading to loss of $\mathrm{Fe}^{3+}$ from the heme creating an oxidising environment that disrupts the polarity of membrane phospholipids, particularly flipping of phosphatidylserine to the outer membrane surface. The mutated $\beta$-globin molecule also undergo auto-oxidation to form the superoxide $\left(\mathrm{O}_{2}-\right.$ ) produced during reoxygenation of $\mathrm{Hb}$ to form methaemoglobin, which in the presence of hydrogen peroxide $\left(\mathrm{H}_{2} \mathrm{O}_{2}\right)$ decomposes the $\mathrm{Hb}$ releasing free iron to create a highly oxidising microenvironment [38]. $\mathrm{Ca}^{2+}$-calmodulin complex activates the erythrocyte adenosine monophosphate deaminase (AMPD) and increases the 
intracellular level of inosine monophosphate (IMP) from deamination of AMP, rendering the cell energy deficient and in turn increasing the translocation of phosphatidyl-serine to the outer membrane surface [39]. These processes results in RBC membrane fragility and eventual haemolysis.

\section{Pathophysiology of vaso-oclussion}

RBCs fragility and stiffness are both respectively responsible for the haemolysis and obstruction of microcirculation that results in vaso-oclussion, both of which characterise the pathophysiological bases of SCD. Vaso-oclussion arises due to adhesion of sickled RBCs to the endothelium of micro-vessels resulting in the obstruction of blood flow and subsequently ischemia in affected tissues. Vaso-oclusion is propagated in two phases. In the first, the reticulocytes produced prematurely in the bone marrow in an attempt to relieve anaemic stress adhere to blood vessels with the aid of various adhesion proteins expressed on their cell surfaces. This reduces the velocity of RBC in the microcirculation, maintaining the RBC in a hypoxic environment long enough for the formation of deoxy- $\mathrm{HbS}$ and $\mathrm{Hb}$ polymerization into fibres. In the second phase, sickled $\mathrm{RBCs}$ are entrapped in the micro vessels by binding to endothelial cells via different adhesion proteins [40]. Sickle RBC binding to the endothelium is facilitated by processes and factors such as the Von Willebrand factor (vWF) bridging intergrin receptors with similar receptors on endothelial cells of large vessels, binding of $\alpha 4 \beta 1$ on sickled RBC to vascular cell adhesion molecule 1 (VCAM-1) on endothelial cells in micro-vessels, bridging of CD36 on sickled RBC with $\alpha \mathrm{v} \beta 3$ integrin receptor on endothelial cells by plasma thrombospondin and binding of sickled RBCS to E- and P-selectins on cytokine activated endothelium [41].

It is known that the endothelium plays a crucial role in development of vaso-oclussion by mediating RBC adhesion through the expression of several adhesion molecules/receptors such as VCAM-1,
Lu/BCAM, c-type lectins (selectins), and CD36 on the surfaces of endothelial cells, and the molecular mechanisms that triggers endothelial activation till date are not fully understood [42]. In SCD, the activation of endothelial cells result in endothelial dysfunction and aberrant adhesion molecule expression often characterising a deviation from basal quiescent state of endothelium to a more active state [42]. This activation is believed to be triggered in part by processes due to sickled RBCs haemolysis such as heme liberation and release of inflammatory cytokines from cytolysed sickled RBCs. In a murine sickle cell model, heme activated nuclear factor kappa- $\beta$ (NFk $\beta$ ) of endothelial cells causes degranulation of Weibel-Palade body (WPB) by mobilising WPB, VWF and P-selectin to the surface of the cells and endothelial walls through the action of toll-like receptor 4 (TLR4) [43]. Oxygen radicals produced from the interactions of sickled RBCs with the endothelium and subsequent activation of endothelial $N_{k} \beta$ also up-regulate the transcription of adhesion molecules such as VCAM1, E-selectin and ICAM1 giving the circulating endothelial cells an activated phenotype through the expression of these adhesion molecules (Figure 2) [44, 45]. Pand E-selectin have been suggested to be potential factors in the development of vaso-oclussion but the implication of P-selectin in the pathogenesis of vaso-oclussion and as a potential therapeutic target is further emphasised by reduced sickled RBC and leukocyte adhesion to endothelium and increased microvascular blood flow in SCD mice treated with anti-P-selectin antibody [46]. We are also of the opinion that inflammatory cytokines produced during infection and during RBC haemolysis play significant roles in the expression endothelial cell adhesion molecules/receptors.

An in vitro study also demonstrated the role of platelets in endothelial activation in SCD patients since platelets circulate in an activated form in these patients. Steady state SCA platelets co-cultured with human umbilical endothelial cells (HUVEC) ac- 
Figure 2: Schematic illustration of proposed mechanisms underlying increased adhesion of sickled RBCs to vascular endothelium and vaso-constriction leading to episodic pain syndromes, leg ulcers and organ dysfunctions in SCD: Rupture of RBCs could result in systemic infection anaemia and release of cellular molecules such as heme, arginase, superoxides and inflammatory cytokines. This could lead to activation of NFk $\beta$ and reduced NO production through release of the cellular molecules or increased production of immature reticulocytes consequent of anaemia. These factors thus could result in increased expression of adhesion molecules that will mediate binding of sickled RBCs to endothelial surface of the vasculature causing vasoocclusive episodes.

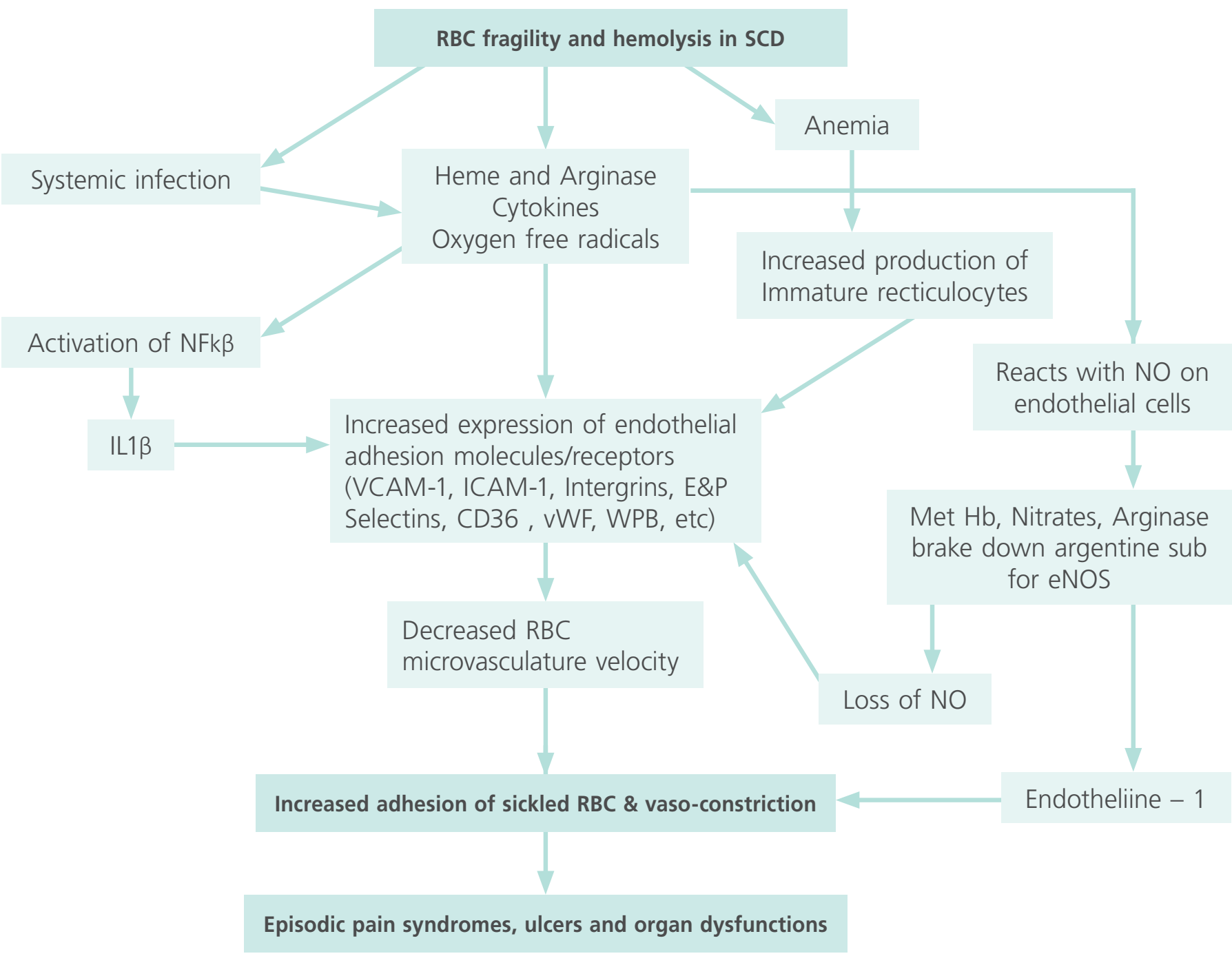

eNOS $=$ endothelial nitric oxide synthase,$I L 1 \beta=$ Interleukin -1 beta, RBC $=$ Red blood cell , SCD = Sickle cell disease, NFk $\beta-$ nuclear factor kappa beta VCAM-1 = vascular cellular adhesion molecule 1, ICAM-1 = intracellular adhesion molecule -1, E\&P Selectins, vWF = Von Willebrand factor, WPB = Weibel-Palade body, $\mathrm{NO}=$ nitric oxide, E-Selectins $=$ endothelial-leukocyte adhesion molecule 1. 
tivated the endothelial cells (EC) through activation of EC NFk $\beta$ and increased IL1 $\beta$ expression and a resulting high expression of adhesion molecules such as ICAM1 and E-selectin [47].

Aside endothelial activation, endothelial dysfunction which is characterised by the reduction in NO produced by endothelial cells is another contributor to development of vaso-oclusion. $\mathrm{NO}$ is a major vasodilator produced by nitric oxide synthase (NOS) through conversion of arginine to citrulline. $\mathrm{NO}$, after production traverses the endothelial cell membranes to bind guanylate cyclase converting GTP to cGMP in smooth muscle cells, subsequently activating cGMP-dependent protein kinases that mediates vasodilation. During haemolysis, there is release of heme and arginase into the circulatory system. Heme reacts with NO forming nitrates and metHb while arginase breaks down arginine which is a substrate for NOS to replenish the scavenged NO (Figure 2) [48, 49]. This in turns leads to increased expression of endothelin-1, a vasoconstrictor, resulting in vasoconstriction and vaso-oclusion. Interestingly, it has been previously demonstrated that NOS gene therapy down-regulates the expression of ICAM1, VCAM1, E- and P-selectin, and inhibits the activation of platelets $[50,51]$. This then suggests a role for $\mathrm{NO}$ in endothelial inactivation and further strengthens the fact that reduced bioavailability of NO in SCD may contribute to platelet activation and increased expression of adhesion molecules.

\section{Current and emerging therapeutic strategies in the treatment of SCD}

Fundamentally, apart from the prophylactic treatment such as Pneumococcal vaccination and penicillin injection given to SCD infant during early diagnosis, the treatment of SCD is based on either disease management procedure or a curative stem cell therapy (all discussed below), both of which exhibit a level of complications that are currently being investigated.

\section{Prophylactic therapy}

There are currently three prophylactic treatments that are widely accepted and predominantly in use; penicillin prophylaxis, pneumococcal vaccination and folate supplement. Penicillin prophylaxis is provided to infants shortly after birth and diagnosis of SCD. This is because within the first 5 years of life, SCD patients are prone to life threatening pneumonia infection due to vaso-oclusion in the spleen preventing antibody production against encapsulated micro-organisms such as Streptococcal pneumonia and Haemophilus influenza, and inability of the spleen to also produce complement factors and C-reactive proteins for bacteria sensing, recognition and phagocytosis. This thus result in chronic infection that can lead to death in the first $24 \mathrm{hrs}$ from onset of the infection [52-54]. Immediately after diagnosis or at least by 2 months of age, SCD patients under the age of 5 years are treated with $125 \mathrm{mg}$ of penicillin VK twice daily. This dosage is increased to $250 \mathrm{mg}$ twice daily for patients over the age of 5 [54]. Because of the decline in episodes of infection in older SCD patients and ability to develop immune response, penicillin prophylaxis is advised to be discontinued to prevent development of resistant strains.

Pneumococcal infection is a common occurrence in SCD patients and the use of pneumococcal vaccines widely is to prevent this in SCD patients under 5 years of age. The vaccination involves immunisation with a heptavalent protein conjugate vaccine (PCV7) at ages 2, 4, 6 and 12 months. This is followed with immunisation with a tricosavalent pneumococcal polysaccharide vaccine at 2 and 5 years [55]. Because of the increased rate of folate turn over due to megaloblastic anaemia and bone marrow aplasia associated with haemolytic anaemia, SCD patients are treated with $1 \mathrm{mg}$ of folate daily [56].

In addition to the above therapeutic combination, because of the prevalence of malaria amongst SCD patient in Nigeria and other parts of Sub Sa- 
hara Africa, treatment with anti-malaria prophylaxis is often recommended to reduce episodes of crisis [57]. The most commonly used treatment ranges from combination of arthemisin based drugs to the use of insecticide treated nets. Chemoprophylaxis with proguanil or pyrimethamine is also widely used and has been found to reduce sickle cell crises [57, 58]. Daily dosage of 100 or $200 \mathrm{mg}$ of proguanil or weekly dosage of 125 or $250 \mathrm{mg}$ mefloquine have also been shown to reduce sickle cell crises with at least $80 \%$ success rate and both regimen having comparable outcomes [59].

\section{SCD treatments aimed at disease management \\ Hydroxyurea for $\mathrm{HbF}$ induction}

In the first few months to couple of years of life, new born with SCD are prevented from vaso-oclusive and anaemic crises that characterise SCD due to the expression of $\mathrm{HbF}$. HbF interferes with $\mathrm{HbS}$ polymerisation preventing the formation of deo$\mathrm{xy}-\mathrm{HbF}$ polymeric fibre at a concentration that is enough to have toxic effect on the RBC. It has been reported that in compound heterozygotes of SCD trait having hereditary persistence of $\mathrm{HbF}$ expression is advantage. Twenty percent $\mathrm{HbF}$ is enough to prevent SCD crises even when there is about $80 \% \mathrm{HbS}$ in the RBC [60]. Erythroid progenitors have high $\mathrm{HbF}$ levels and due to stringent differentiation and slow clonal expansion, only about 3\% of circulating RBCs of adults contain a detectable concentration of HbF. Thus with rapid expansion of progenitor cells, the retention of $y$-globin gene expression of $\mathrm{HbF}$ in $\mathrm{RBC}$ is maintained. Therefore, drugs such as 5-azacytidine and its analogues have been developed to induce expression of $\mathrm{HbF}$ through destruction of late erythroid progenitors that favour expression of $\beta$-globin gene of adult $\mathrm{Hb}$. This results in accelerated expansion of erythroid progenitors into RBCs containing high $\mathrm{HbF}$ levels. Due to gross gene hypomethylation and cytotoxicity of these class of drug, their use in the treatment of SCD is currently not approved. Hydroxyurea is the only drug approved for $\mathrm{HbF}$ induction to prevent vaso-oclussive crises and perhaps the most successful drug in the treatment of SCD [58]. Hydroxurea acts by inhibiting ribonucleotide reductase, an enzyme that converts ribonucleotides to deoxyribonucleotides, thus, halting DNA synthesis [58].

Treatment with hydroxyurea is applicable to SCD patients of all ages [61] and it is recommended subsequent to presentation of symptoms such as priapism, persistent anaemia, vaso-oclussion related crises (more than 3 hospital admissions per year) and ACS. Starting dose of hydroxyurea is $15 \mathrm{mg} /$ $\mathrm{Kg} /$ day which is increased by $5 \mathrm{mg} / \mathrm{Kg} /$ day every 3 months up to a maximum of $35 \mathrm{mg} / \mathrm{Kg} /$ day. Because of the effect of the drug on hematopoiesis, patients are closely monitored at 2 week intervals for complete blood counts to detect bone marrow aplasia. In adults that cannot tolerate the starting dosage, $500 \mathrm{mg} /$ day dosage can be applied and the blood count checked fortnightly in many Sub Saharan centres. In the event of myelotoxicity, the drug is withheld for 2 weeks until stable blood count is achieved. When recurrent or persistent myelotoxicity occur, dosage may be reduced gradually by $2.5 \mathrm{mg} / \mathrm{Kg} /$ day until stable conditions are observed. Afterwards complete blood count may be monitored monthly for changes in platelet and leukocyte counts.

Hydroxyurea is a well-tolerated drug and treatment with hydroxyurea is associated with significant reduction in hospital admissions due to vaso-occlusive crises, ACS, priapism and hepatic complications [56]. Its effectiveness in preventing stroke is controversial anyway [62], but a clinical trial investigating this is currently underway [63]. On the contrary, there is increasing evidence that long term use of hydroxyurea has suggested by some studies, results in leukaemia in patients with essential thrombocytemia and polycythemia vera $[64,65]$, although a study involving 299 adult SCD patients found no association 
between 9 years treatment with hydroxyurea and development of leukaemia of any sort [66]. Thus, there is need for a well-structured long term study that will further investigate association between treatment with hydroxyurea and leukomogenic risk in SCD patients.

\section{Replenishment of circulating NO for vaso-occlusion treatment}

$\mathrm{NO}$ is a known major vasodialator produced by endothelial cells and it plays a key role in vasoocclusive crises of $\operatorname{SCD}[67,68]$. Although there is increased expression of NOS in SCD, the disease is characterised with inactivation of NOS, resistance to $\mathrm{NO}$ and impaired NO bioavailability resulting in vaso-occlusive related crises such as pulmonary hypertension and ACS $[34,69,70]$. As such, different studies have been designed to target increasing the bioavailability of circulating NO to compensate for the deficiency thus observed. A study showed that inhalation of NO significantly reduced the dependence of patient on morphine for pain relief after 6 hours of NO inhalation $(0.26 \mathrm{mg} / \mathrm{kg}$ vs $0.44 \mathrm{mg} / \mathrm{kg}$, case vs placebo group respectively, $p=0.03$ ) and a $1 \mathrm{~cm} / \mathrm{h}$ reduction in pain score compared to placebo group ( $p=0.02$ ) [71]. Because of the important role played by arginine in the biosynthesis of $\mathrm{NO}$ and pathogenesis of vaso-occlusion in SCD, several studies now look at the use of arginine supplements in treating vaso-occlusion. However, no standard dosage exists as yet. Patients treated with oral 100 $\mathrm{mg} / \mathrm{kg}$ of L-arginine $\mathrm{HCl}$ thrice daily for 5 days had $15.2 \%$ reduction in arterial systolic pressure (63.9 $\pm 13 \mathrm{mmHg}$ to $54.2 \pm 12 \mathrm{mmHg}, p=0.002$ ) (72). A recent randomised control trial reported that 100 $\mathrm{mg} / \mathrm{Kg}$ L-arginine supplementation reduces opioid use for pain relief by $54 \%(1.9 \pm 2.0 \mathrm{mg} / \mathrm{kg}$ vs 4.1 $\pm 4.1 \mathrm{mg} / \mathrm{kg}$, admission vs discharge respectively, $p$ $=0.02)$ and $50 \%$ reduction in pain score $(1.9 \pm 2.4$ vs. $3.9 \pm 2.9$, admission vs discharge respectively, $p$ $=0.01$ ) [73].

\section{RBC transfusion}

$\mathrm{RBC}$ transfusion in treating $\mathrm{SCD}$ is a major disease management procedure in adult patients with disease complications and vaso-occlusive crises and about $90 \%$ of adults suffering from SCD will receive this treatment at some point in their lives [74]. However, there is need to thoroughly consider the risks and benefits of the procedure to maintain a risk-benefit balance and avoid further disease complications and waste of resources. The major risks associated with transfusion include iron overload, increased blood viscosity, alloimmunisation against donor blood cells and delayed haemolytic transfusion reactions. Nonetheless, the requirement and recommendations for the use of $\mathrm{RBC}$ in treating SCD is increasing due to increased sophistication in the procedure with the availability of iron chelators and erythrocytapheresis to treat iron overload as well as extended phenotype matching for alleviating alloimmunisation.

Indications for the recommendation of RBC transfusion include transient RBC aplasia, ACS, splenic sequestration induced hypovolemia, acute multi-organ failure and stroke, acute exacerbation of anaemia and pre-surgery blood transfusion for SCD patients [74-76]. Irrespective of the cause or requirement for transfusion, the need for the procedure should be based on the inability of the patient to compensate for the loss of $\mathrm{Hb}$ due to anaemia. As asymptomatic patients with moderate or even severe anaemia have a steady state reduction in $\mathrm{Hb}$ level, undergoing transfusion can lead to unwarranted and avoidable complications. Simple RBC transfusion are frequently used in event of acute splenic sequestration and transient RBC aplasia but patients with the latter are transfused with adequate monitoring of the $\mathrm{Hb}$ level which will increase as the disease alleviates. Transfusion with aliquots of $5 \mathrm{ml} / \mathrm{Kg}$ spaced over some hours up till $\mathrm{Hb}$ level rises to $10 \mathrm{mg} / \mathrm{dl}$ so as to avoid hyperhemoglobinemia post-transfusion due to disease alleviation [77]. In patients with acute ischemic stroke, chronic 
transfusion can be used to prevent future episodes of the disease and can also prevent the disease development in high risk patients diagnosed early with transcranial Doppler ultrasonography [78] but recent studies have shown that patients that undergo chronic transfusion for prevention of recurrent stroke often develop cerebral vasculopathy and cerebral infarction [79-82].

\section{Emerging treatment strategies Use of African traditional medicines}

There are some African traditional medicines that have shown great potentials in the stimulation of hematopoietic cells to rapidly produce blood and correct anaemia. It has also been suggested that they may be acting by increasing the population of circulating $\mathrm{HbF}$. They may also be acting on any of the molecular pathways described above. However, these traditional medicines need purification to isolate active ingredient(s) and subjected to clinical trials before they can be widely used in SCD treatment.

\section{Hematopoietic stem cell transplantation (HSCT) and gene therapy}

HSCT is the only curative measure available for SCD treatment and considering the prevalence of the disease, it is still an underutilised form of treatment. Recommendation of HSCT is often limited because of rare existence of HLA-matched sibling donor (MSD). Apart from this, there are some associated complications such as graft versus host disease (GVHD) and post-HSCT toxicity. Children below 16 years stand a high chance of having successful HSCT due to absence of age-related comorbidities and organ failure. Advancement in research could help push the application of the procedure to older age groups with the use of reduced intensity treatment (RIT), a multistep strategy where immunosuppressive agents are used in low doses to prevent organ toxicities [83]. RIT procedures vary for each patient and the procedure is not to be considered the same across population. In adult patients with advanced disease comorbidities, HSCT often results in high morbidity and mortality rate. However, presentation with recurrent stroke, hypertension and renal dysfunction, or patients at high risk of pulmonary complications and sudden death, qualifies for consideration for the procedure as benefits of performing HSCT can outweigh the complications. In this case, a matched unrelated donor (MUD) can be considered with the implementation of RIT if there is no MSD, showing the potential of using this treatment modality to increase donor pool irrespective of HLA status. A RIT trial in 14 patients treated with fludarabine, alemtuzumab and melphalan using MSD or MUD marrow produced a 95\% overall and 79\% event free survival rate in these patients [14]. RIT HSCT trials are currently underway at the National Institutes of Health and Blood and Marrow Transplant-Related Clinical Trials Network (BMT CTN) Sickle Cell Unrelated Transplant (SCURT) and it is currently in practice at the John Hopkins School of Medicine [84].

Apart from RIT-HSCT, a recent study showed that genetically modifying $\beta$-globin (autologous hematopoietic stem cell gene therapy) and subsequently transferring this gene into bone marrow stem cell to be transplanted could help reduce post-HSCT complications and other associated morbidities [85]. A lentiviral vector encoding wild type human $\mathrm{Hb}$ gene modified to impair HbS polymerisation was transferred into bone marrow CD34 to transduce the patients' HbS and thus prevent formation of sickled RBC. This study showed efficient transfection of the lentiviral vector and effective transduction of SCD bone marrows' CD34 progenitor to produce normal $\mathrm{Hb}$ and this could be moving into clinical trial soon.

\section{Conclusions}

In summary, the burden of SCD in sub-Saharan region of Africa is enormous. Emotional, financial 
and total healthcare costs are monumental. Unfortunately, despite the burden of SCD in sub-Saharan Africa, there are no centres offering these new treatments methods or currently using molecular approaches in the treatment of SCD. Although more awareness about SCD and its complications is increasing in the region, research focusing on modern treatment methods is almost non existence. Targeting adhesion molecules known to circulate in the blood of SCD patients and or expressed on endothelial cells may lead to the development of treatments that will see a reduction in adhesion of sickled RBCs to the endothelium hence preventing vaso-oclusive episodes. Periodic monitoring of their plasma levels using molecular methods and subsequent administration of neutralizing antibodies may be a potent preventive measure. New research focusing on the molecular mechanism of vaso-oclusive syndromes may lead to further identification of molecular targets that can improve SCD treatments in the sub-Saharan region of Africa. SCD being a single gene defect will be adequately treated using the newly developed stem cell gene therapy and HSCT in sub-Saharan region of Africa.

\section{Conflict of interest}

We the authors declare that we have no conflict of interest.

\section{References}

1. Rees DC, Williams TN, Gladwin MT. Sickle-cell disease. Lancet. 2010; 376(9757): 2018-31.

2. Steinberg $\mathrm{MH}$. Predicting clinical severity in sickle cell anaemia. British journal of haematology. 2005; 129(4): 465-81.

3. Jiskoot PM, Halsey C, Rivers R, Bain BJ, Wilkins BS. Unusual splenic sinusoidal iron overload in sickle cell/haemoglobin D-Punjab disease. Journal of clinical pathology. 2004; 57(5): 539-40.

4. Maeda K, Kini RK, Saeed SM, Rucknagel DL. Hemoglobin SO Arab and hemoglobin CO Arab diseases. Clinical and laboratory study. The American journal of pediatric hematology/oncology. 1983; 5(2): 127-31.

5. Lionnet F, Hammoudi N, Stojanovic KS, Avellino V, Grateau G, Girot $R$, et al. Hemoglobin sickle cell disease complications: a clinical study of 179 cases. Haematologica. 2012; 97(8): 1136-41.

6. Stuart MJ, Nagel RL. Sickle-cell disease. The Lancet. 2004; 364(9442): 1343-60

7. Piel FB, Patil AP, Howes RE, Nyangiri OA, Gething PW, Williams TN, et al. Global distribution of the sickle cell gene and geographical confirmation of the malaria hypothesis. Nature communications. 2010; 1: 104.

8. Makani J, Cox SE, Soka D, Komba AN, Oruo J, Mwamtemi H, et al. Mortality in sickle cell anemia in Africa: a prospective cohort study in Tanzania. PloS one. 2011; 6(2): e14699.

9. CDC. Global health Nigeria: Sickle Cell Disease Atlanta, USA: Centers for Disease Prevention and Control; 2012 [updated 2012; cited 2014 19, June]. Available from: http://www.cdc.gov/ globalhealth/countries/nigeria/what/scd.htm.

10. Grosse SD, Odame I, Atrash HK, Amendah DD, Piel FB, Williams TN. Sickle cell disease in Africa: a neglected cause of early childhood mortality. American journal of preventive medicine. 2011; 41(6 Suppl 4): S398-405.

11. WHO. Management of birth defects and haemoglobin disorders: Report of a Joint WHO-March of Dimes meeting. Geneva, Switzerland. 2006.

12. Yanni E, Grosse SD, Yang Q, Olney RS. Trends in pediatric sickle cell disease-related mortality in the United States, 1983-2002. The Journal of pediatrics. 2009; 154(4): 541-5.

13. Quinn CT, Rogers ZR, McCavit TL, Buchanan GR. Improved survival of children and adolescents with sickle cell disease. Blood. 2010; 115(17): 3447-52.

14. Shenoy S. Hematopoietic stem cell transplantation for sickle cell disease: current practice and emerging trends. Hematology/ the Education Program of the American Society of Hematology American Society of Hematology Education Program. 2011; 2011: 273-9. 
15. Jacobs P, Wood L. Immunohematopoietic stem cell transplantation: introduction and 35 years of development in South Africa--the historical and scientific perspective. Bone marrow transplantation. 2008; 42 Suppl 1: S125-s32.

16. Galadanci N, Wudil BJ, Balogun TM, Ogunrinde GO, Akinsulie A, Hasan-Hanga F, et al. Current sickle cell disease management practices in Nigeria. International health. 2014; 6(1): 23-8.

17. Ballas SK, Lieff S, Benjamin LJ, Dampier CD, Heeney MM, Hoppe $C$, et al. Definitions of the phenotypic manifestations of sickle cell disease. American journal of hematology. 2010; 85(1): 6-13.

18. Elenga N. Delayed Hemolytic Transfusion Reaction in Sickle Cell Disease. American Journal of Clinical Medicine Research. 2013; 1(3): 40-4.

19. Al-Salem AH. Splenic complications of sickle cell anemia and the role of splenectomy. ISRN hematology. 2011; 2011: 864257.

20. Owusu-Ofori S, Hirst C. Splenectomy versus conservative management for acute sequestration crises in people with sickle cell disease. The Cochrane database of systematic reviews. 2013; 5: CD003425.

21. Nolan VG, Wyszynski DF, Farrer LA, Steinberg MH. Hemolysisassociated priapism in sickle cell disease. Blood. 2005; 106(9): 3264-7

22. Vichinsky EP, Neumayr LD, Earles AN, Williams R, Lennette $E T$, Dean D, et al. Causes and outcomes of the acute chest syndrome in sickle cell disease. National Acute Chest Syndrome Study Group. The New England journal of medicine. 2000; 342(25): 1855-65.

23. Gladwin MT, Vichinsky E. Pulmonary complications of sickle cell disease. The New England journal of medicine. 2008; 359(21): 2254-65

24. Kato GJ, Gladwin MT, Steinberg MH. Deconstructing sickle cell disease: reappraisal of the role of hemolysis in the development of clinical subphenotypes. Blood reviews. 2007; 21(1): 37-47.

25. Sharpe CC, Thein SL. Sickle cell nephropathy - a practical approach. British journal of haematology. 2011; 155(3): 287-97.

26. Gladwin MT, Sachdev $V$, Jison ML, Shizukuda Y, Plehn JF, Minter $K$, et al. Pulmonary hypertension as a risk factor for death in patients with sickle cell disease. The New England journal of medicine. 2004; 350(9): 886-95.

27. Platt OS, Thorington BD, Brambilla DJ, Milner PF, Rosse WF, Vichinsky $E$, et al. Pain in sickle cell disease. Rates and risk factors. The New England journal of medicine. 1991; 325(1): 11-6.

28. Frenette PS. Sickle cell vaso-occlusion: multistep and multicellular paradigm. Current opinion in hematology. 2002; 9(2): 101-6.

29. Heffner KL, France CR, Trost Z, Ng HM, Pigeon WR. Chronic low back pain, sleep disturbance, and interleukin-6. The Clinical journal of pain. 2011; 27(1): 35-41

30. Wratney AT, Gentile MA, Hamel DS, Cheifetz IM. Successful treatment of acute chest syndrome with high-frequency oscillatory ventilation in pediatric patients. Respiratory care. 2004; 49(3): 263-9
31. De Franceschi L, Cappellini MD, Olivieri O. Thrombosis and Sickle Cell Disease. Semin Thromb Hemost 2011; 37: 11.

32. Jones $\mathrm{H}$, Blinder $\mathrm{M}$, Anadkat $\mathrm{M}$. Cutaneous Manifestations of Sickle Cell Disease. Open Journal of Blood Diseases. 2013; 3: 6.

33. Johnson MC, Kirkham FJ, Redline S, Rosen CL, Yan Y, Roberts I, et al. Left ventricular hypertrophy and diastolic dysfunction in children with sickle cell disease are related to asleep and waking oxygen desaturation. Blood. 2010; 116(1): 16-21.

34. Farmakis D, Aessopos A. Pulmonary hypertension associated with hemoglobinopathies: prevalent but overlooked. Circulation. 2011; 123(11): 1227-32.

35. Dean D, Neumayr L, Kelly DM, Ballas SK, Kleman K, Robertson $S$, et al. Chlamydia pneumoniae and acute chest syndrome in patients with sickle cell disease. Journal of pediatric hematology/ oncology. 2003; 25(1): 46-55.

36. Vichinsky E, Williams R, Das M, Earles AN, Lewis N, Adler A, et al. Pulmonary fat embolism: a distinct cause of severe acute chest syndrome in sickle cell anemia. Blood. 1994; 83(11): 3107-12.

37. Bogdanova A, Makhro A, Wang J, Lipp P, Kaestner L. Calcium in red blood cells-a perilous balance. International journal of molecular sciences. 2013; 14(5): 9848-72.

38. Aslan M, Thornley-Brown D, Freeman BA. Reactive species in sickle cell disease. Annals of the New York Academy of Sciences. 2000; 899: 375-91.

39. Sabina RL, Wandersee NJ, Hillery CA. Ca2+-CaM activation of AMP deaminase contributes to adenine nucleotide dysregulation and phosphatidylserine externalization in human sickle erythrocytes. British journal of haematology. 2009; 144(3): 434-45.

40. Odievre $\mathrm{MH}$, Verger E, Silva-Pinto AC, Elion J. Pathophysiological insights in sickle cell disease. The Indian journal of medical research. 2011; 134: 532-7.

41. Walmet PS, Eckman JR, Wick TM. Inflammatory mediators promote strong sickle cell adherence to endothelium under venular flow conditions. American journal of hematology. 2003; 73(4): 215-24.

42. Kato GJ, Martyr S, Blackwelder WC, Nichols JS, Coles WA, Hunter LA, et al. Levels of soluble endothelium-derived adhesion molecules in patients with sickle cell disease are associated with pulmonary hypertension, organ dysfunction, and mortality. British journal of haematology. 2005; 130(6): 943-53.

43. Belcher JD, Chen C, Nguyen J, Milbauer L, Abdulla F, Alayash Al, et al. Heme triggers TLR4 signaling leading to endothelial cell activation and vaso-occlusion in murine sickle cell disease. Blood. 2014; 123(3): 377-90

44. Kaul DK, Finnegan E, Barabino GA. Sickle red cell-endothelium interactions. Microcirculation. 2009; 16(1): 97-111. 
45. Madigan C, Malik P. Pathophysiology and therapy for haemoglobinopathies; Part I: sickle cell disease. Expert reviews in molecular medicine. 2006; 8(09): 1-23.

46. Gutsaeva DR, Parkerson JB, Yerigenahally SD, Kurz JC, Schaub RG, Ikuta $T$, et al. Inhibition of cell adhesion by anti-P-selectin aptamer: a new potential therapeutic agent for sickle cell disease. Blood. 2011; 117(2): 727-35.

47. Proenca-Ferreira R, Brugnerotto $A F$, Garrido $V T$, Dominical VM, Vital DM, Ribeiro Mde F, et al. Endothelial activation by platelets from sickle cell anemia patients. PloS one. 2014; 9(2): e89012.

48. Kyle Mack A, Kato GJ. Sickle cell disease and nitric oxide: a paradigm shift? The international journal of biochemistry \& cell biology. 2006; 38(8): 1237-43.

49. Schaer DJ, Buehler PW, Alayash Al, Belcher JD, Vercellotti GM. Hemolysis and free hemoglobin revisited: exploring hemoglobin and hemin scavengers as a novel class of therapeutic proteins. Blood. 2013; 121(8): 1276-84.

50. Ferroni P, Vazzana N, Riondino S, Cuccurullo C, Guadagni F, Davi G. Platelet function in health and disease: from molecular mechanisms, redox considerations to novel therapeutic opportunities. Antioxidants \& redox signaling. 2012; 17(10): 1447-85

51. Qian H, Neplioueva V, Shetty GA, Channon KM, George SE. Nitric oxide synthase gene therapy rapidly reduces adhesion molecule expression and inflammatory cell infiltration in carotid arteries of cholesterol-fed rabbits. Circulation. 1999; 99(23): 2979-82

52. Pearson HA. Prevention of pneumococcal disease in sickle cell anemia. The Journal of pediatrics. 1996; 129(6): 788-9.

53. Pai VB, Nahata MC. Duration of penicillin prophylaxis in sickle cell anemia: issues and controversies. Pharmacotherapy. 2000; 20(1): 110-7.

54. Cober MP, Phelps SJ. Penicillin prophylaxis in children with sickle cell disease. The journal of pediatric pharmacology and therapeutics: JPPT: the official journal of PPAG. 2010; 15(3): 152-9.

55. American Academy of Pediatrics. Committee on Infectious Diseases. Policy statement: recommendations for the prevention of pneumococcal infections, including the use of pneumococcal conjugate vaccine (Prevnar), pneumococcal polysaccharide vaccine, and antibiotic prophylaxis. Pediatrics. 2000; 106(2 Pt 1): 362-6.

56. Aliyu ZY, Tumblin AR, Kato GJ. Current therapy of sickle cell disease. Haematologica. 2006; 91(1): 7-10.

57. Oniyangi $O$, Omari AA. Malaria chemoprophylaxis in sickle cell disease. The Cochrane database of systematic reviews. 2006(4): CD003489.

58. Meremikwu MM. Sickle cell disease. Clinical evidence. 2009; 2009 .
59. Nwokolo C, Wambebe C, Akinyanju O, Raji AA, Audu BS, Emodi IJ, et al. Mefloquine versus Proguanil in Short-Term Malaria Chemoprophylaxis in Sickle Cell Anaemia. Clin Drug Investig. 2001; 21(8): 537-44.

60. Steinberg MH, Forget BG, Higgs DR, Weatherall DJ. Disorders of hemoglobin: genetics, pathophysiology, and clinical management: Cambridge University Press; 2009.

61. Ware RE. How I use hydroxyurea to treat young patients with sickle cell anemia. Blood. 2010; 115(26): 5300-11.

62. Sumoza A, de Bisotti R, Sumoza D, Fairbanks V. Hydroxyurea (HU) for prevention of recurrent stroke in sickle cell anemia (SCA). American journal of hematology. 2002; 71(3): 161-5.

63. ClinicalTrials.gov. Sickle Cell Disease - Stroke Prevention in Nigeria Trial (SPIN); Identifier NCT01801423: National Institutes of Health (US); February 26, 2013. Available from: http:// clinicaltrials.gov/ct2/show/NCT01801423.

64. Sterkers Y, Preudhomme C, Lai JL, Demory JL, Caulier MT, Wattel $E$, et al. Acute myeloid leukemia and myelodysplastic syndromes following essential thrombocythemia treated with hydroxyurea: high proportion of cases with 17p deletion. Blood. 1998; 91(2): 616-22.

65. Weinfeld A, Swolin B, Westin J. Acute leukaemia after hydroxyurea therapy in polycythaemia vera and allied disorders: prospective study of efficacy and leukaemogenicity with therapeutic implications. European journal of haematology. 1994; 52(3): 134-9.

66. Steinberg MH, Barton F, Castro O, Pegelow CH, Ballas SK, Kutlar A, et al. Effect of hydroxyurea on mortality and morbidity in adult sickle cell anemia: risks and benefits up to 9 years of treatment. JAMA: the journal of the American Medical Association. 2003; 289(13): 1645-51.

67. Wood KC, Hsu LL, Gladwin MT. Sickle cell disease vasculopathy: a state of nitric oxide resistance. Free radical biology \& medicine. 2008; 44(8): 1506-28.

68. Aslan M, Ryan TM, Townes TM, Coward L, Kirk MC, Barnes S, et al. Nitric oxide-dependent generation of reactive species in sickle cell disease. Actin tyrosine induces defective cytoskeletal polymerization. The Journal of biological chemistry. 2003; 278(6): 4194-204.

69. Aslan M, Freeman BA. Oxidant-mediated impairment of nitric oxide signaling in sickle cell disease--mechanisms and consequences. Cellular and molecular biology. 2004; 50(1): 95105.

70. Reiter CD, Wang X, Tanus-Santos JE, Hogg N, Cannon RO, 3rd, Schechter $A N$, et al. Cell-free hemoglobin limits nitric oxide bioavailability in sickle-cell disease. Nature medicine. 2002; 8(12): 1383-9.

71. Weiner DL, Hibberd PL, Betit P, Cooper AB, Botelho CA, Brugnara C. PReliminary assessment of inhaled nitric oxide for acute vaso-occlusive crisis in pediatric patients with sickle cell disease. JAMA: the journal of the American Medical Association. 2003; 289(9): 1136-42. 
72. Morris CR, Morris SM, Jr., Hagar W, Van Warmerdam J, Claster S, Kepka-Lenhart D, et al. Arginine therapy: a new treatment for pulmonary hypertension in sickle cell disease? American journal of respiratory and critical care medicine. 2003; 168(1): 63-9.

73. Morris CR, Kuypers FA, Lavrisha L, Ansari M, Sweeters N, Stewart $M$, et al. A randomized, placebo-controlled trial of arginine therapy for the treatment of children with sickle cell disease hospitalized with vaso-occlusive pain episodes. Haematologica. 2013; 98(9): 1375-82.

74. Chou ST. Transfusion therapy for sickle cell disease: a balancing act. Hematology / the Education Program of the American Society of Hematology American Society of Hematology Education Program. 2013; 2013: 439-46.

75. Wanko SO, Telen MJ. Transfusion management in sickle cell disease. Hematology/oncology clinics of North America. 2005; 19(5): 803-26, v-vi.

76. Vichinsky EP, Haberkern CM, Neumayr L, Earles AN, Black D, Koshy $\mathrm{M}$, et al. A comparison of conservative and aggressive transfusion regimens in the perioperative management of sickle cell disease. The Preoperative Transfusion in Sickle Cell Disease Study Group. The New England journal of medicine. 1995; 333(4): 206-13.

77. Smith-Whitley K, Thompson AA. Indications and complications of transfusions in sickle cell disease. Pediatric blood \& cancer. 2012; 59(2): 358-64.

78. Adams RJ, McKie VC, Hsu L, Files B, Vichinsky E, Pegelow C, et al. Prevention of a first stroke by transfusions in children with sickle cell anemia and abnormal results on transcranial Doppler ultrasonography. New England Journal of Medicine. 1998; 339(1): 5-11.

79. Bishop S, Matheus MG, Abboud MR, Cane ID, Adams RJ, Jackson SM, et al. Effect of chronic transfusion therapy on progression of neurovascular pathology in pediatric patients with sickle cell anemia. Blood cells, molecules \& diseases. 2011; 47(2): 125-8

80. Gyang E, Yeom K, Hoppe C, Partap S, Jeng M. Effect of chronic red cell transfusion therapy on vasculopathies and silent infarcts in patients with sickle cell disease. American journal of hematology. 2011; 86(1): 104-6.

81. Hulbert ML, McKinstry RC, Lacey JL, Moran CJ, Panepinto JA, Thompson AA, et al. Silent cerebral infarcts occur despite regular blood transfusion therapy after first strokes in children with sickle cell disease. Blood. 2011; 117(3): 772-9.

82. Brousse V, Hertz-Pannier L, Consigny $Y$, Bresson J-L, Girot $R$, Mirre $E$, et al. Does regular blood transfusion prevent progression of cerebrovascular lesions in children with sickle cell disease? Annals of hematology. 2009; 88(8): 785-8.
83. Shenoy S, Grossman WJ, DiPersio J, Yu LC, Wilson D, Barnes YJ, et al. A novel reduced-intensity stem cell transplant regimen for nonmalignant disorders. Bone marrow transplantation. 2005; 35(4): 345-52.

84. Bolanos-Meade J, Fuchs EJ, Luznik L, Lanzkron SM, Gamper CJ, Jones RJ, et al. HLA-haploidentical bone marrow transplantation with posttransplant cyclophosphamide expands the donor pool for patients with sickle cell disease. Blood. 2012; 120(22): 4285-91.

85. Romero Z, Urbinati F, Geiger S, Cooper AR, Wherley J, Kaufman $\mathrm{ML}$, et al. $\beta$-globin gene transfer to human bone marrow for sickle cell disease. The Journal of Clinical Investigation. 2013; 123(8): 14.

\section{Comment on this article:}

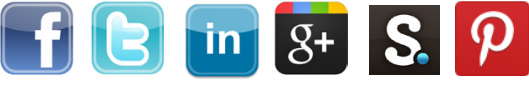

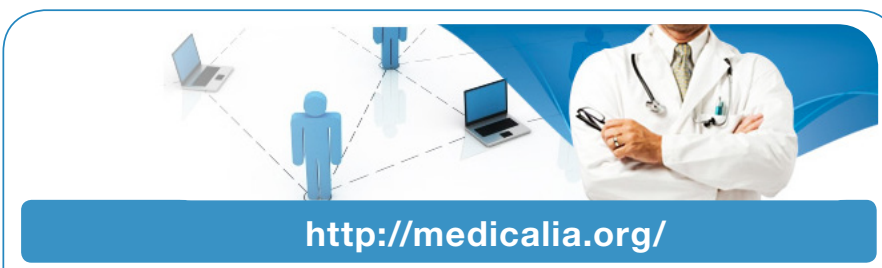

Where Doctors exchange clinical experiences, review their cases and share clinical knowledge. You can also access lots of medical publications for free. Join Now!

\section{Publish with iMedPub}

\section{http://www.imed.pub}

International Archives of Medicine is an open access journal publishing articles encompassing all aspects of medical science and clinical practice. IAM is considered a megajournal with independent sections on all areas of medicine. IAM is a really international journal with authors and board members from all around the world. The journal is widely indexed and classified Q1 in category Medicine. 